\title{
sciendo
}

\section{Screening for Bioflocculant-Producing Bacteria from the Marine Environment of Sodwana Bay, South Africa}

\author{
Anthony M. Ugbenyen ${ }^{1}$, John J. Simonis ${ }^{2}$, Albertus K. Basson ${ }^{3}$ \\ ${ }^{1}$ Department of Biochemistry, Edo University Iyamho, Uzaurea-Auchi, Edo-State, Nigeria. \\ ${ }^{2}$ Department of Hydrology, University of Zululand, KwaDlangezwa, KZN, South Africa. \\ ${ }^{3}$ Department of Biochemistry and Microbiology, University of Zululand, KwaDlangezwa, KZN, South Africa.
}

Received $3^{\text {rd }}$ Oct. 2017, Accepted $9^{\text {th }}$ Mar. 2018

DOI: 10.2478/ast-2018-0010

*Corresponding author

A.M.Ugbenyene-mail: ugbenyenanthony@gmail.com ugbenyen.anthony@edouniversity.edu.ng

Tel: $+234-8138071549$

\begin{abstract}
Flocculants are chemicals that mediate flocculation process, by aggregating colloids from suspension to form floc. Chemical flocculants are hazardous to the environment, which inform the search for safer and eco-friendly alternatives from microorganisms. Bacterial strains were isolated from water and sediment samples collected from Sodwana Bay, South Africa, and physiological properties of the bacterial strains were observed. Flocculation test using kaolin clay suspension was done on all isolates and the ones that showed flocculating activity were identified molecularly using 16 rRNA gene sequence analysis. Forty marine bacteria isolates were gotten from sediments and water samples collected from Sodwana Bay. Most of the isolates exhibited a range of colony pigmentation (pink, creamy, yellow, and white). After purification of individual isolates, they were screened for their potential to produce bioflocculant. The result revealed that isolates marked SOD3, SOD10, SOD12, SOD26, SOD27, SOD28, SOD32, SOD33 and SOD34 produced bioflocculants as shown by the flocculating activities from their crude extract. All these isolates showed good flocculation of kaolin clay suspension above $60 \%$ (flocculating activity) except SOD12. These bioflocculant producing isolates were identified as Pseudoalteromonas sp, Alcaligenes faecalis, Bacillus subtilis, Bacillus cereus, Bacillus stratosphericus. The results showed Sodwana Bay, South Africa as a reservoir of bacteria with potential to produce flocculants. However, further studies on the optimisation of culture conditions for bioflocculant production, extraction, characterisation and application of isolates is on the way to underscore the biotechnological importance of these microbes as producers of substitutes to harmful chemical flocculants commonly used in water and wastewater treatment.
\end{abstract}

Keywords: Marine; Bacteria; Bioflocculant; Sediment; Sodwana Bay. 


\subsection{Introduction}

The marine environment could be seen as a repository of many novel microorganisms that have potential to produce secondary metabolites (Bredholt et al., 2008). The marine realm covers enormous amount of the earth's surface and high volume of its crust (70\% and $90 \%$ respectively), thus providing the largest inhabitable space for microorganisms (Lam, 2006; Fenical, 1993). It is regarded as heavily complex and contains various assemblage of life forms that have adapted to extreme environmental conditions such as temperature, pressure and salinity. Marine environmental conditions usually differ from terrestrial, which could confer unique characteristics to marine microorganisms that enables them produce different new biologically active compounds (Stach $e t$ al., 2003; Lam, 2006). An important characteristic for taxonomy and identification of products and functions, is in the isolation of new microorganisms. (Alain and Querellou, 2009).

In the field of microbiology, microorganisms of interest are usually isolated using general and selective media. In the last two decades, the presence of microbes which could not be cultivated in the environment is now made possible by a culture- independent method (Christen, 2008). There are new technologies for isolation of microorganisms, which includes micro-encapsulation techniques, fluorescence-activated cell sorting, micromanipulation techniques, diffusion chambers, floating filter method, and high throughput extinction-culturing methods (Alain and Querellou, 2009; Brehm-Stecher and Johnson, 2004). Pure culture isolates of bacterial species from different environmental sources is crucial in all the various branches of the field of microbiology since bacteria are found almost everywhere and live in consortium with other microbial communities.

Bioflocculation is the process whereby flocculation is mediated in the presence of microorganisms and/or their metabolite products (bioflocculants) (Tyagiet et al., 2009). It involves the removal of colloidal particles from solution by these metabolites products of the microorganisms, with or without the subsequent biodegradation of the colloidal particles (Tyagiet et al., 2009). The production and usage of bioflocculants has gained much attention and research recently because of its biodegradability, harmlessness and lack of secondary pollution (Gong et al., 2008). When used in dewatering and downstream processing it is inert and safe compared to chemical flocculants that are not readily biodegradable and some of their monomeric products are neurotoxic and even show strong human carcinogenic potential (Shih et al., 2001). Due to the neurotoxic, carcinogenic and non-biodegradability of chemical flocculants, attention is shifting toward safer and more eco-friendly alternative derived from microorganisms. This has led researchers to isolate, screen and identify microorganisms with potential to produce bioflocculant.

The present study aimed to isolate microorganisms from water and sediment samples collected from Sodwana Bay, South Africa and screen them for bioflocculant producing potential. After screening, nine out of the forty isolated strains produced bioflocculants and showed very good flocculation of kaolin clay. These nine isolate where then selected and identified using $16 \mathrm{~S}$ rRNA gene sequence.

\subsection{Materials and Methods 2.1 Collections of Samples}

Six different Seawater and sediment samples were randomly collected from approximately 0 to $20 \mathrm{~m}$ off shore of the Sodwana Bay using water and sediment samplers. The collected samples were transported in ice to the Hydrology and Microbiology laboratories of the University at Zululand, KwaDlangezwa, South Africa. Sediment samples were dried overnight at $30{ }^{\circ} \mathrm{C}$.

\subsection{Isolation and screening of microorganism}

Microorganisms were isolated using an agar plate culture containing medium with composition of meat extract-1.0 g, peptone- $5.0 \mathrm{~g}$, yeast extract-2.0 g, NaCl-8.0 g and agar-15.0 g per litre of filtered seawater according to the methods described by Jensen et al. (1991). Microorganisms were originally screened based on colony morphology. Two loopfuls of bacterial colonies were then grown in $50 \mathrm{ml}$ of screening medium according to Zhang et al. (2007) and Ugbenyen et al (2012) with slight modifications on a rotary shaker $(160 \mathrm{rpm})$ at $30^{\circ} \mathrm{C}$ for $72 \mathrm{~h}$. The medium contained $(\mathrm{g} / \mathrm{L}$ of filtered natural sea water): glucose-20; casein0.7 ; yeast extract-0.5; $\mathrm{KH}_{2} \mathrm{PO}_{4}-2 ; \mathrm{K}_{2} \mathrm{HPO}_{4}-5 ; \mathrm{NaCl}-0.1$ and $\mathrm{MgSO}_{4}$ $7 \mathrm{H}_{2} \mathrm{O}-0.2$. At the end of incubation period, $2 \mathrm{~mL}$ of the fermentation broth was centrifuged $(8.0 \mathrm{~g}, 30 \mathrm{~min})$ to separate the cells, and the cell free culture supernatant was analysed for flocculating activity. Finally, isolates with good flocculating activity for kaolin was selected for further study. The pre-culture was stored at $4{ }^{\circ} \mathrm{C}$ and used for subsequent inoculations.

\subsection{Flocculating activity experiment}

Flocculating activity was measured according to the method described elsewhere (Kurane et al., 1986; Zhang et al., 2007; Cosa et al., 2011; Ugbenyen et al., 2012) with slight modifications. Briefly, $3 \mathrm{~mL}$ of $1 \%$ $\mathrm{CaCl}_{2}$ and $2 \mathrm{~mL}$ of cell free supernatant were added to $100 \mathrm{~mL}$ kaolin suspended solution $(4 \mathrm{~g} / \mathrm{L})$ in $250 \mathrm{~mL}$ flask. The mixture was stirred vigorously, poured into a $100 \mathrm{~mL}$ cylinder and allowed to stand for $5 \mathrm{~min}$. The absorbance of the clarifying solution (at $550 \mathrm{~nm}$ ) was measured spectrophotometrically. A control experiment was performed using the same method, but with fresh culture medium replacing the cell-free supernatant. The flocculating activity was calculated according to the equation:

Flocculating activity $(\%)=\left(\frac{B-A}{B}\right) \times 100$

where $\mathrm{A}$ is the absorbance at $550 \mathrm{~nm}$ of the sample and $\mathrm{B}$ is the absorbance at $550 \mathrm{~nm}$ of the control experiment.

\subsection{Identification of Bioflocculant Producing Microorganisms}

\subsubsection{DNA Extraction}

DNA extraction was done for selected isolates showing good potential for the production of bioflocculant using ZR fungal/bacterial DNA MiniPrep ${ }^{\mathrm{TM}}$ Kit from Zymo Research, Inc. The extraction protocol was performed according to the instruction of the manufacturer.

\subsubsection{Polymerase Chain Reaction (PCR) Amplification of 16S rRNA} Gene

PCR amplification was carried out in $50 \mu \mathrm{L}$ reaction volume of Dream $\mathrm{Taq}^{\mathrm{TM}}$ Green PCR Master Mix containing $0.4 \mathrm{mM}$ of each dNTP, $4 \mathrm{mM}$ 
$\mathrm{MgCl}_{2}, 0.2 \mu \mathrm{L}$ Dream Taq ${ }^{\mathrm{TM}}$ polymerase, $1 \mu \mathrm{M}$ of each forward and reverse universal primer (F:5'-ATGCCATAGCATTTTTATCC-3'), (R:5'-GATTTAATCTGTATCAGG-3') and $1 \mu \mathrm{g}$ template DNA. The PCR condition include an initial denaturation $\left(95^{\circ} \mathrm{C}\right.$ for $\left.3 \mathrm{~min}\right), 25$ cycles of denaturation $\left(95{ }^{\circ} \mathrm{C}\right.$ for $\left.30 \mathrm{sec}\right)$, annealing $\left(56^{\circ} \mathrm{C}\right.$ for $\left.30 \mathrm{sec}\right)$ and extension $\left(72^{\circ} \mathrm{C}\right.$ for $\left.1 \mathrm{~min}\right)$, and a final extension $\left(72{ }^{\circ} \mathrm{C}\right.$ for $\left.5 \mathrm{~min}\right)$.

\subsubsection{PCR Products Sequence}

The PCR product sequence was done at the facilities of Inqaba Biotech Laboratories, Pretoria, South Africa using a sequencer. The 16S rRNA gene sequences obtained was compared with others in the NCBI genebank database with Basic Alignment Search Tool (BLAST) according to Stephen et al., (1997).

Table 1: Morphology of Bacteria Isolates from Sodwana Bay

\begin{tabular}{|c|c|c|c|}
\hline Isolate No & Type of Sample & Morphology/Colour & Pigmentation \\
\hline SOD1 & Sediment & Glistening pink colour, & Pinkish \\
\hline SOD2 & Sediment & Creamy serrated edges & Creamy \\
\hline SOD3 & Sediment & Moderate cream & Creamy white \\
\hline SOD4 & Sediment & Creamy white swarming colony & Creamy \\
\hline SOD5 & Sediment & Creamy tiny small colonies & Creamy \\
\hline SOD6 & Sediment & Translucent creamy colour & Creamy \\
\hline SOD7 & Sediment & Flat whitish serrated colony & Creamy \\
\hline SOD8 & Sediment & Whitish creamy swarming edged colony & Creamy \\
\hline SOD9 & Sediment & Creamy white swarming colony & Creamy \\
\hline SOD10 & Sediment & Light brown smooth and glistering colony & Clear \\
\hline SOD11 & Sediment & Flat creamy swarming colony & Creamy \\
\hline SOD12 & Sediment & Creamy branching mycelia colony & Creamy \\
\hline SOD13 & Sediment & Pink, smooth glistening colony & Pinkish \\
\hline SOD14 & Sediment & Creamy & Creamy \\
\hline SOD15 & Water & Creamy white & Creamy \\
\hline SOD16 & Water & Creamy white & No pigmentation \\
\hline SOD17 & Water & Creamy branching leaf like colony & Creamy \\
\hline SOD18 & Water & Whitish swarming and branching edge colony & Creamy white \\
\hline SOD19 & Water & Light creamy smooth edges & Creamy \\
\hline SOD20 & Water & Creamy white serrated edge colony & Creamy \\
\hline SOD21 & Estuary Water & Creamy serrated edge colony & Creamy white \\
\hline SOD22 & Water & Creamy serrated edge colony & No pigmentation \\
\hline SOD23 & Water & Whitish creamy serrated edge colony & Creamy \\
\hline SOD24 & Water & Creamy white branching edge colony & Creamy white \\
\hline SOD25 & Water & Dry whitish raised round colony & Creamy \\
\hline SOD26 & Water & Creamy, moderate edge colony & Creamy \\
\hline SOD27 & Estuary water & Creamy serrated edge colony & Creamy \\
\hline SOD28 & Water & Whitish creamy serrated edge & Creamy \\
\hline SOD29 & Water & White swarming edge colony & Creamy \\
\hline SOD30 & Water & Lightish creamy colony & No pigment \\
\hline SOD31 & Water & Yellow glistering rough edge colony & Yellowish \\
\hline SOD32 & Estuary & Whitish creamy, swarming colony & Creamy \\
\hline SOD33 & Estuary & Whitish cream serrated edge colony & Creamy \\
\hline SOD34 & Estuary & Creamy swarming edge colony & Creamy \\
\hline SOD35 & Water & Creamy & Creamy \\
\hline SOD36 & Water & Yellow glistering round edge colony & yellowish \\
\hline SOD37 & Estuary & Pink, smooth glistering colony & Pink \\
\hline SOD38 & Water & Creamy white swarming colony & Whitish creamy \\
\hline SOD39 & Water & Translucent creamy serrated edge colony & No pigment \\
\hline SOD40 & Water & Whitish serrated colony & Whitish \\
\hline
\end{tabular}




\subsection{Results and Discussion}

It is well documented that soil, water and activated sludge samples collected from terrestrial habitats have been found to be good sources for isolating flocculant-producing microorganisms (Fujita et al., 2000; Lu et al., 2005; Gao et al., 2006; Yim et al., 2007; Gong et al., 2008). It has also been reported that there is a decrease in the rate of new metabolite isolated from microorganism of terrestrial origin. Rather what have been observed is an increases re-isolation of already known compounds (Fenical et al., 1999; Ugbenyen et al., 2012). This suggests that more research should focus on exploring under-exploited habitat like the marine environment for isolation of novel microorganisms for new bioactive compounds. The present study explores the marine environment of Sodwana Bay, South Africa, as a source of bacterial isolates with potentials to produce bioflocculant.

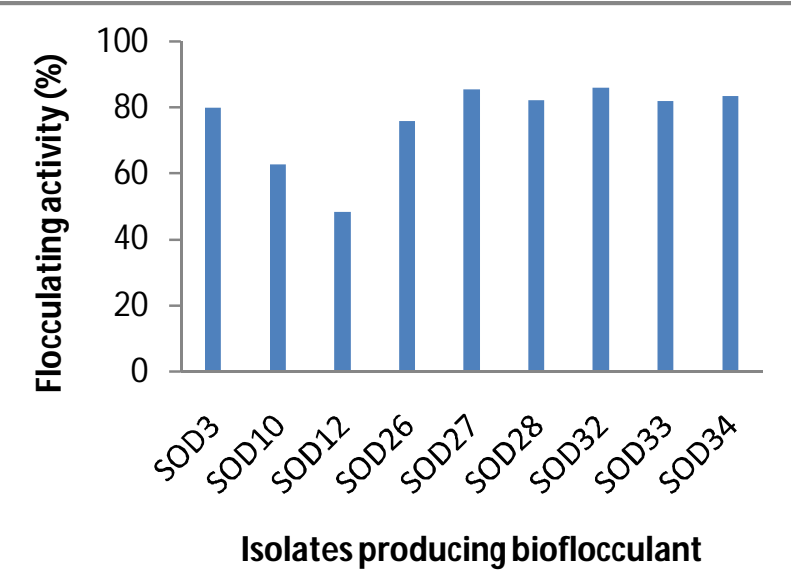

Figure 1: Flocculating activities of bioflocculant-producing isolates from Sodwana bay. FA is the flocculating activity in percentage. SOD3Pseudoalteromonassp; SOD10-Alcaligenesfaecalis; SOD12Alcaligenesfaecalis; SOD26- Bacillus subtilis; SOD27- Bacillus cereus; SOD28- Bacillus cereus; SOD32- Bacillus cereus; SOD33- Bacillus cereus; SOD34-Bacillus stratosphericus.

In this study, after screening forty marine isolates (Table 1), only nine where found to produce bioflocculants (Figure 1). All bioflocculantproducing isolates SOD 3 , SOD 10, SOD 26, SOD 27, SOD 28, SOD 32 , SOD 33 and SOD 34, showed good flocculating activities above $60 \%$, except SOD 12. The advantages bioflocculant possess as an inert and greener flocculant over chemical flocculants which have been implicated in health problems (Dearfield and Abermathy, 1988; Kowall et al., 1989) is the main aim for screening these isolates. Approximately, 25\% of the total isolate, produces bioflocculants indicating that Sodwana Bay is a reservoir of bacteria with bioflocculant potential.

Identification by $16 \mathrm{~S}$ rRNA gene revealed that of the nine (9) bioflocculant-producing isolates, Bacillus species were more predominant followed by Alcaligenes and Pseudoalteromonas species (Table 2). The genus Bacillus comprises of about 60 species which are gram positive rod-shaped bacteria that have been implicated in bioflocculant production (Salehizadeh and Shojaosadati, 2002; Ugbenyen et al., 2013; Ugbenyen et al., 2014). From identification results of bioflocculant-producing strains, the following Bacillus species were identified: Bacillus subtilis, Bacillus cereus, Bacillus stratosphericus, confirming these genera as producers of bioflocculant.
Table 2: Molecular Identification of Bacteria Isolates with Bioflocculant-Potential

\begin{tabular}{|lll|}
\hline Isolate No & Location & $\begin{array}{l}\text { Identification by 16S } \\
\text { rRNA }\end{array}$ \\
\hline SOD3 & Marine sediment & $\begin{array}{l}\text { Pseudoalteromonas sp } \\
\text { SOD12 } 10\end{array}$ \\
Marine sediment & Alcaligenes faecalis \\
SOD 26 & Marine sediment & Alcaligenes faecalis \\
SOD 28 & Marine water & Bacillus subtilis \\
SOD 32 & Estuary & Bacillus cereus \\
SOD 33 & Marine water & Bacillus cereus \\
SOD 34 & Estuary & Bacillus cereus \\
\hline
\end{tabular}

On the other hand, Alcaligenes faecalis a gram-negative rod-like bacterium was also isolated from the marine environment of Sodwana Bay as a producer of bioflocculant. This further confirmed the findings of Shimiziu (1985), who earlier reported that Alcaligenes faecalis produces bioflocculant. Pseudoalteromonas sp. was another bacterium identified as a producer of bioflocculant from this study; it is a rod-shaped, gramnegative bacteria. It is interesting to note, that Dufourcq et al., (2013), also isolated Pseudoalteromonas sp. from a marine coastal environment and found them to be a rich source of bioactive compounds. This suggests that the bacterium is predominant in the marine environment.

\subsection{Conclusion}

The present study indicate that, Sodwana Bay, South Africa is a reservoir of bacteria with potential to produce bioflocculants. However, further studies on the optimization of culture conditions for bioflocculant production, extraction, characterisation and application of the bioflocculants produced by these isolates will be done to underscore the biotechnological importance of these microbes as producers of alternative substitutes to the harmful chemical flocculants commonly used in water and wastewater treatment.

\section{Acknowledgement}

We are grateful to the University of Zululand, South Africa for financial support.

\section{Conflict of Interest}

Authors declare no conflict of interest.

\section{Authors Contribution}

Conception: AMU, JJS and AKB; Design: AMU; Execution: AMU Interpretation: $\mathrm{AMU}, \mathrm{JJS}$ and $\mathrm{AKB}$; Writing the paper: $\mathrm{AMU}$

Proofreading the paper: JJS and AKB 


\section{References}

Alain, K., and Querellou, J., 2009. Cultivating the uncultured: limits, advances and future challenges. Extremophiles, 13, 583-594

Bredholt, H., Fjaervik, E., Johsen, G., and Ztchev, S.B., 2008. Actinomycetes from sediments in Trondheim Fjord Norway: Diversity and Biological Activity. Mar. Drugs 6(1), 12-24.

Brehm-Stecher, B.F., and Johnson E.A., 2004. Single Cell Microbiology: Tools, Technologies and Applications. Microbiol. Mol. Biol. Rev. 68, 538-559.

Cosa, S., Mabinya, L.V., Olaniran, A.O., Okoh, O.O., Bernard, K., Deyzel, S., and Okoh, A.I., 2011. Bioflocculant production by Virgibacillus sp. Rob Isolated from the Bottom Sediment of Algoa Bay in the Eastern Cape, South Africa. Molecule, 16, 2431-2442

Christen, R. 2008, Global sequencing: a review of current molecular data and new methods available to assess microbial diversity. Microbes Environ., 23, 253-268

Dearfield, K.L., and Abermathy, C.O., 1988. Acrylamide: its metabolism developmental and reproductive effects, genotoxicity and carcinogenicity. Mutat. Res., 195, 45-77

Dufourcq, R., Chalkiadakis, E., Fauchon, M., Deslandes, E., Kerjean, V., Chanteau, S., Petit, E., Guezennec, J., and Dupont-Rouzeyrol, M., 2013. Isolation and partial characterization fbacteria (Pseudoalteromonas sp.) with potential antibacterial activity from a marine costal environment from New Caledonia. Lett. Appl. Microbiol., 58, 102-108.

Fenical, W., 1993. Chemical studies of marine bacteria: developing a new resource. Chem. Rev. 93, 1673-1683.

Fenical, W., Baden, D., Burg, M., de Goyet, C.V., Grimes, J.D., Katz, M., Marcus, N.H., Pomponi, S., Rhines, P., Tester P., and Vena, J., 1999. Marine-derived pharmaceuticals and related bioactive compounds. In: From Monsoons to microbes: understanding the Ocean's Role in Human Health. Edited by Fenical W.National Academics Press. pp. 71-86.

Fujita, M., Ike, M., Tachibana, S., Kitada, G., Kim, S.M., and Inoue, Z., 2000. Characterization of a bioflocculant produced by Citrobactersp. TKF04 from acetic acid and propionic acids. J. Biosci. Bioeng., 89, $40-46$.

Gao, J., Bao, H., Xin, M., Liu, Y., Li, Q., and Zhang, Y., 2006. Characterization of a bioflocculant from a newly isolated Vagococcus sp. W31. J Zhejiang Univ. Sci. B. 7, 186-192.

Gong, W., Wang, S., Sun, X., Liu, X., Yue, Q., and Gao, B., 2008. Bioflocculant production by culture of Serratiaficaria and its application in wastewater treatment. Bioresour. Technol., 99, 46684674.

Jensen, P.R., Dwight, R., and Fenical, W., 1991. Distribution of actinomycetes in near-shore tropical marine sediments. Appl. Environ. Microbiol., 57, 1102-1108.

Kowall, N.W., Pendleury, W.W., and Kessler, J.B., 1989. Aluminiuminduced neurofibrillary degeneration affects a subset of neurons in rabbit cerebral cortex, basal forebrain and upper brain stem. Neurosci., 29, 329-337.

Kurane, R., Takeda, K., and Suzuki, T., 1986. Screening for characteristics of microbial flocculants. Agric. Biol. Chem., 50, 23012307.
Lam, K.S., 2006. Discovery of novel metabolites from marine actinomycetes. Ind. Microbiol., 9, 245-251.

Lu, W.Y., Zhang, T., Zhang, D.Y., Li, C.H., Wen, J.P., and Du, L.X., 2005. A novel bioflocculantproduced by Enterobacteraerogenesand its use in defecating the trona suspension. Biochem. Eng. J., 27, 1-7.

Salehizadeh, H., and Shojaosadati, S.A., 2002. Isolation and characterisation of a bioflocculant produced by Bacillus firmus. Biotechnol. Lett., 24, 35-40.

Shih, I. L., Van, Y. T., Yeh, L. C., Lin, H. G., and Chang, Y. N., 2001. Production of a biopolymer flocculant from Bacillus licheniformis and its flocculation properties. Bioresour. Technol., 78, 267-272.

Shimiziu, N., 1985. Floc-forming bacteria isolated from activated sludge in high BOD loading treatment. J. Ferment. Technol. 63, 67-71.

Stach, J.E., Maldonado, L.A., Masson, D.G., Ward, A.C., Goodfellow, M., and Bull, A., 2003. Statistical approaches for estimating actinobacterial diversity in marine sediments. Appl. Environ. Microbiol., 69, 6189-6200.

Stephen, F.A., Thomas, L.M., Alejandro, A.S., Jinghui, Z., Zheng, Z., Webb, M., and David, J.L., 1997. Gapped BLAST and PSI-BLAST: a new generation of protein database searchprograms. Nucleic Acids Res., 25, 3389-3402.

Tyagi, R.D., Surampalli, R.Y., Zhang, T.C., Kao, C.M., Lohani, B.N., 2009. Sustainable Sludge Management: Production of Added Products. ASCE. Reston, Virginia pp. 146-156

Ugbenyen, A., Cosa, S., Mabinya, L., Babalola, O.O., Aghdasi, F., and Okoh, A., 2012. Thermostable Bacterial Bioflocculant Produced by Cobetia Spp. Isolated from Algoa Bay (SouthAfrica). Int. J. Environl Res. Public Health, 9(6), 2108-2120.

Ugbenyen, A.M., Cosa, S., Mabinya, L.V., and Okoh, A.I., 2014. Bioflocculant Production by Bacillus sp. Gilbert Isolated from a Marine Environment in South Africa. Appl. Biochem. Micro., 50, 4954.

Ugbenyen, A.M., and Okoh, A.I., 2013. Flocculating Properties of a Bioflocculant Produced by Bacillus sp. isolated from a marine environment in South Africa. Chem. Biochem. Eng. Q., 27(4), 511518.

Yim, J.H., Kim, S.J., Ahn, S.H., and Lee, H.K., 2007. Characterization of novel bioflocculant, p-KG03, from a marine dinoflagellate, Gyrodiumimpudicum KG03. Bioresour. Technol., 98, 361-367.

Zhang, Z., Lin,B., Xia, S., Wang, X., and Yang, A., 2007. Production and application of a novel bioflocculant by multiple-microorganism consortia using brewery wastewater as carbon source. J. Environ. Sci., 19, 667- 673 . 